\title{
The neurological lesion in achalasia of the cardia
}

\author{
BARBARA SMITH \\ From the Department of Pathology, St Bartholomew's Hospital Medical College, London, ECI
}

SUMMARY Achalasia of the cardia is associated with loss of argyrophil cells in the myenteric plexus and a lesion of the vagus. The conditions which could involve the primary and secondary neurone are discussed.

It has been established for many years that achalasia of the cardia is associated with loss or absence of ganglion cells in the myenteric plexus (Rake, 1926; Hurst and Rake, 1930; Lendrum, 1937; Trounce, Deuchar, Kauntze, and Thomas, 1957; Adams, Marples, and Trounce, 1960; Misiewicz, Waller, Anthony, and Gummer, 1969). It is the object of this report to describe the findings on silver impregnation of thick sections both in the myenteric plexus and in the extrinsic parasympathetic nerves, and to discuss the aetiology in the light of these findings.

\section{Material and Methods}

The material available came from one necropsy in which the whole oesophagus was studied and six biopsies taken during cardiomyotomy. In the first case the oesophagus was sampled all the way up by taking large blocks, cutting sections parallel to the myenteric plexus and staining them as described previously (Smith, 1967). The oesophageal biopsies were serially sectioned, about 15 sections of $100 \mu$ being obtainable from each specimen.

\section{Results}

Throughout the alimentary canal the myenteric neurones can be divided into two types on the basis of their affinity for silver, argyrophil and argyrophobe Honjin (1951). Argyrophil cells have usually two or three axons and many dendrites. The dendrites end on argyrophobe cells in the $\stackrel{0}{\vec{\sigma}}$ same ganglion. The axons lead to other ganglia where they branch, going to two or more further ganglia, eventually becoming too fine to follow. As they pass through each ganglion, small branches are given off to its contained neurones. These axons are not seen to leave the myenteric plexus. The branches of the argyrophobe cells $\delta$ cannot be seen on a silver preparation but they can on a cholinesterase, where they form a 의 secondary and tertiary plexus to supply the $D$ smooth muscle cells. On the basis of these anatomical observations it is suggested that the $N$ argyrophil cells act in a supervisory capacity, stimulating the argyrophobe cells which produce $\tilde{D}^{-}$ the acetylcholine which fires the muscle fibre. $\underset{\omega}{N}$ The corollary to this is that loss of argyrophilo cells may have the same clinical effect as totalo neuronal fall-out. The two types of cell cannot be $\mathbb{\Phi}$ distinguished on paraffin section.

The findings were as follows. Paraffin sections of the postmortem material showed a complete absence of neurones, the ganglia being replaced $\stackrel{\odot}{\odot}$ by Schwann cells. There was no inflammatory $\stackrel{2}{\AA}$ infiltration, and silver preparations in five cases (four biopsies and the necropsy case) also showed 8 no neurones. The ganglia contained Schwann cells and small amounts of axonal debris (Fig. 1). (Figure 2shows a normal oesophagus for comparison.) In the necropsy case the changes were uniform throughout the specimen. In most cases a number of varicose axons could be made out within the ganglia which were presumably 


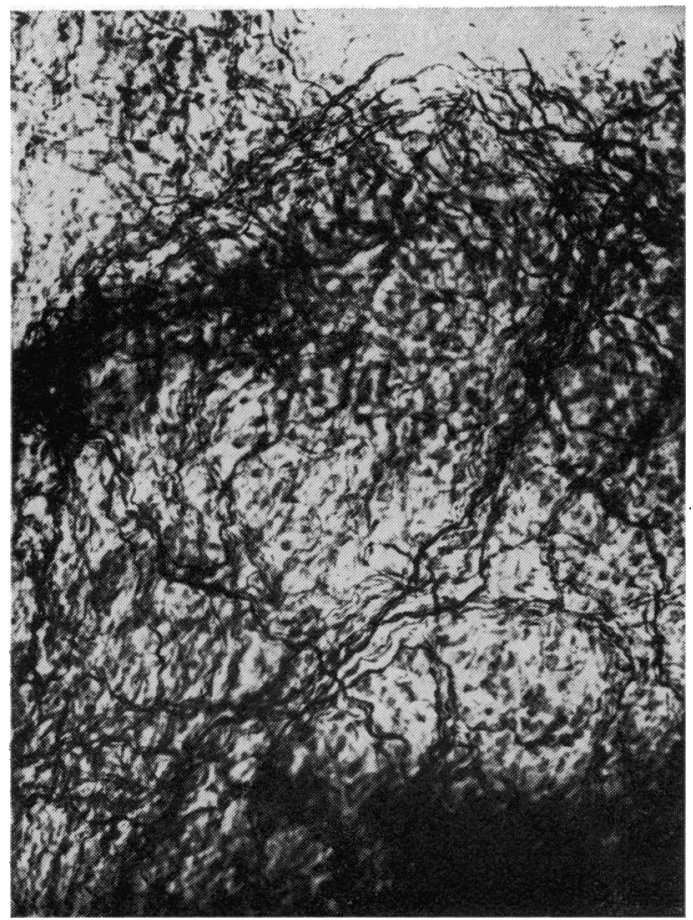

Fig. 1 A myenteric ganglion from a case of achalasia of the cardia. There are no neurones but the network of slightly beaded sympathetic fibres can still be seen. Silver, $\times 120$.

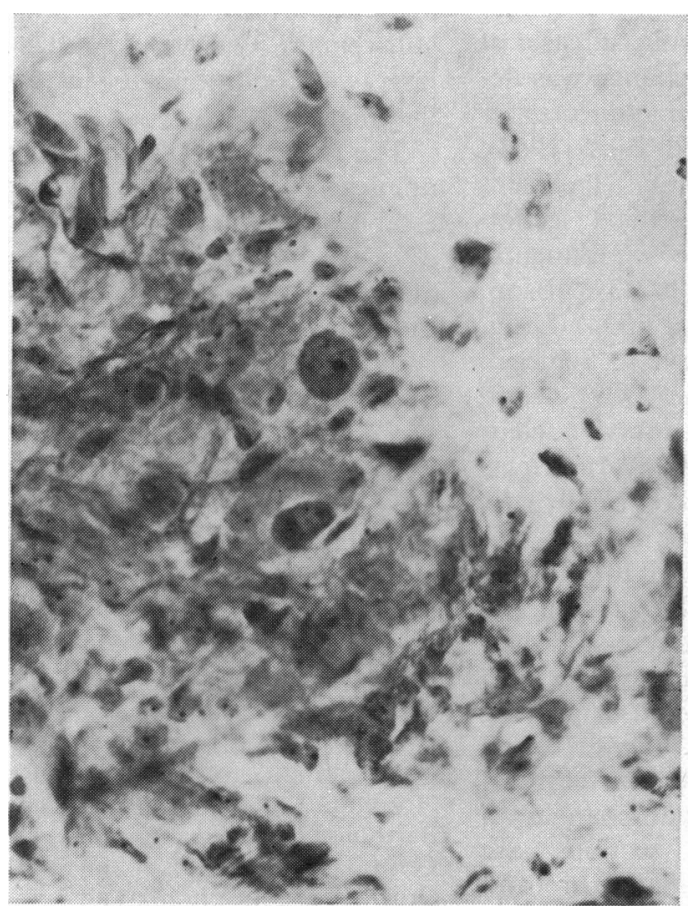

Fig. 3 A myenteric ganglion from a case of achalasia of the cardia. There were no argyrophil cells but two neuronal nuclei of non-argyrophil cells remain. Silver, $\times 525$.

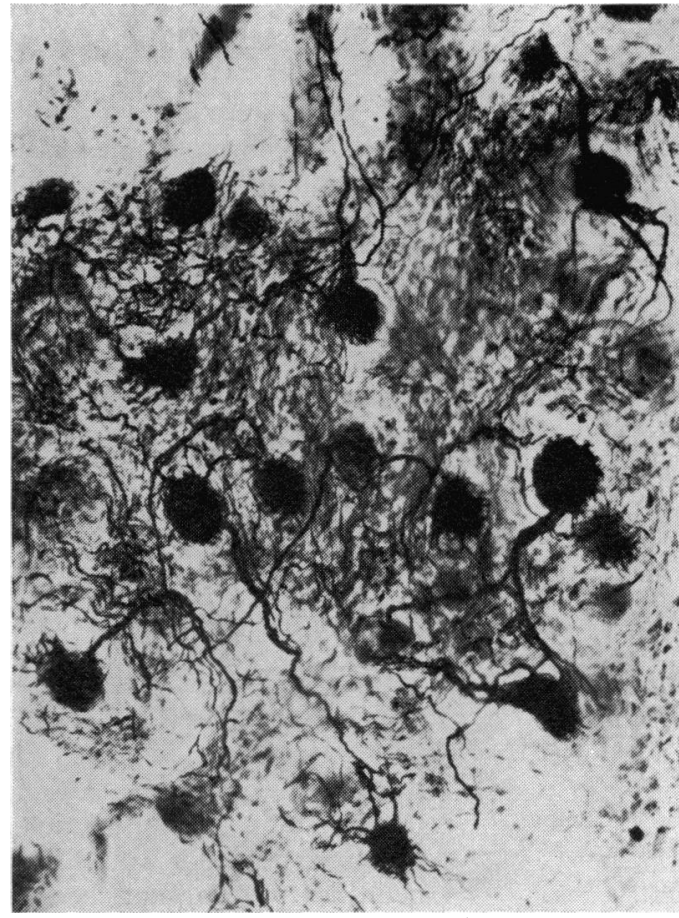

Fig. 2 A myenteric ganglion from a normal oesophagus. Only argyrophil neurones can be seen. Silver, $\times 120$.

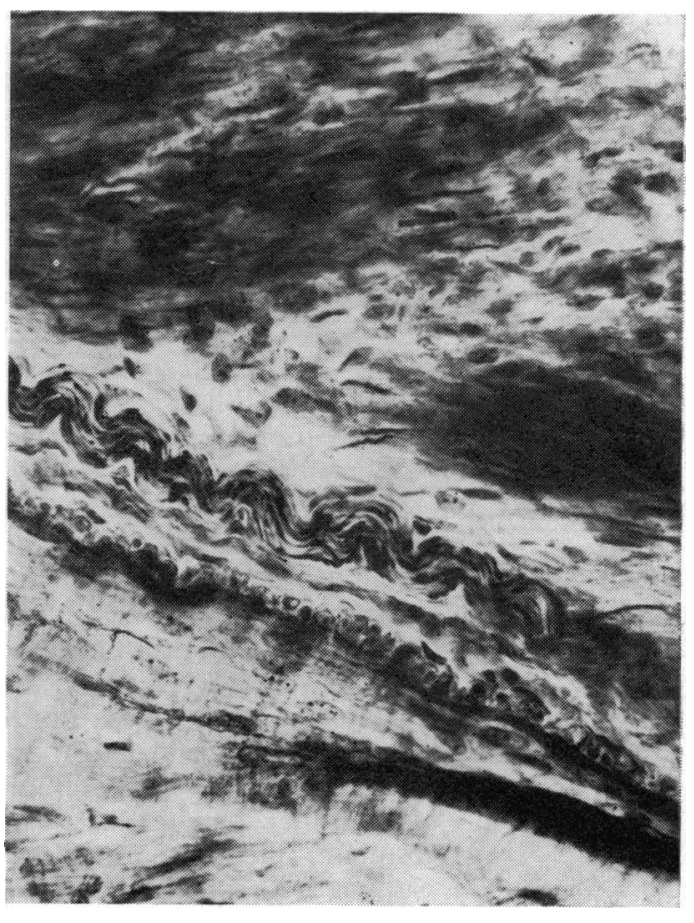

Fig. 4 An extrinsic nerve in the oesophageal wall. Some axons show fragmentation. Silver, $\times 225$.

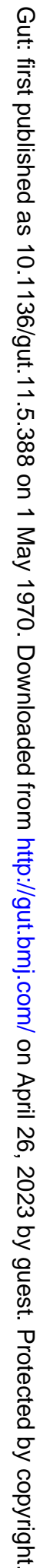


branches of the extrinsic sympathetic supply. In two cases, both biopsies, there were neuronal nuclei still visible among the Schwann cells but there were no argyrophil cells (Figure 3). In the postmortem material and one biopsy, fragmentation was seen in some axons of the extrinsic parasympathetic supply (Figure 4). In the postmortem specimen these fragmented trunks were not plentiful and it must be a very lucky chance for them to appear on a small biopsy. The vagus from the oesophageal wall was examined in paraffin section and by teasing osmium, stained material but no lesion was found.

\section{Discussion}

Trounce et al (1957) have reported some retention of neurones in their series and it was so in two of the specimens described here. They were, however, argyrophobe. An enormous number of transverse $5 \mu$ paraffin sections would have to be examined before it would be possible to say that neurones were absent, because of the sampling error, so that some neuronal persistence may be commoner than has been reported. With the technique used here, the myenteric plexus of the whole oesophagus can be examined on 72 sections.

Two of the cases described here had a lesion in the extrinsic vagal supply. Kraus (1902) described a lesion of the vagus in a case of fusiform gut dilatation. A similar change was described by Heyrovsky (1911), Loeper and Forestier (1921). Cassella, Brown, Sayre, and Ellis (1964), and by Botar and Rubanyi (1965). Transient achalasia has been produced by vagal section by a number of workers in the experimental animal (Carlson and Luckhardt, 1921; Carlson, Boyd, and Pearcey, 1922; Knight, 1934; Long, Nice, Thal, and Truex, 1958; Carveth, Schlegel, Code, and Ellis, 1960). Kimura (1929) found degeneration of neurones in the dorsal nucleus of the vagus as did Cassella et al (1964). Higgs, Kerr, and Ellis (1965) produced electrolytic lesions in the dorsal vagal nucleus of cats and found a reduction of relaxation in the gastrooesophageal sphincter. Other authors, including Lendrum (1937), have failed to find a vagal lesion in their cases. This may be due to technical difficulties. If only the part of the vagus supplying the oesophagus is involved, this is only a fraction of the nerve. Most of the fibres are unmyelinated so that they may not show Wallerian changes on osmium preparations. Paraffin sections are subject to considerable sampling error and fragmenting axons might well be missed, as in motor neurone disease they can be in motor nerves. There is also clinical evidence that the vagus is involved, as some patients with this condition have impairment of reflex gastric secretion in response to insulin (Iordanskaia, 1962; Woolam, Maher, and Ellis, 1967).

If the extrinsic and intrinsic innervation of the oesophagus are both involved in this disease, as seems very probable, the aetiological possibilities are more limited than if only one set of neurones is affected. Hurst and Rake (1930) and Misiewicz et al (1968) described infiltration of the ganglia with lymphocytes. This would tend to suggest an infective or autoimmune origin. Of known infective agents a virus is the most likely, and Symonds (quoted by Hurst and Rake, 1930) suggested that the myenteric neurones might be subject to similar diseases to their homologous structures, the posterior root ganglia. A neurotropic virus such as herpes zoster might attack neurones in the dorsal vagal nucleus and in the myenteric plexus, travelling from one to the other along vagal axons. Neurotropic viruses are known to be very selective in the neurones they will attack.

The other type of condition which can affect both primary and secondary neurones together is a system degeneration of a similar nature to motor neurone disease. Cassella et al (1964) have suggested that the lesion in the brain stem is primary and that the loss of myenteric neurones is due to transsynaptic degeneration. Following lesions of the sacral parasympathetic nerves there is some loss of myenteric neurones in the colon (personal observation). However, this fallout does appear to come on very slowly and even after many years a number of neurones still remain. One would not expect either of the last two conditions to be associated with inflammation.

The differential diagnosis between an infective or degenerative aetiology might be aided by establishing whether or not it is a progressive disorder. Virus infections usually attack all $\bigcirc$ affected neurones over a few days and then $\rightarrow$ the virus disappears leaving only a scar. A system degeneration by its nature picks out $\tilde{N}$ neurones in a progressive fashion, the lesion $N$ becoming continually more severe. Patients with achalasia of the cardia do get progress- $\omega$ ively worse, but the muscular incoordination can be demonstrated at a very early stage and the in- $\stackrel{\varrho}{\mathcal{C}}$ crease in symptoms might well be related to the $\stackrel{\Phi}{\oplus}$ increase in the diameter of the oesophagus and the thickness of its wall. On the whole, both clinical and pathological observations tend to $\mathbb{\mathbb { D }}$ support the infective hypothesis.

I am grateful to Dr R. Banerjee of the London Hospital, Mr J. Griffiths and Mr A. Hunt of St Bartholomew's Hospital, and Dr S. Waller of the음 Central Middlesəx Hospital for the material. Mr P. Crocker took the photographs.

References

Adams, C. W. M., Marples, E. A., and Trounce, J. R. (1960). Achalasia of the cardia and Hirschsprung's disease. The amount and distribution of cholinesterases. Clin. Sci., 19, 473-477. 
Botar, J., and Rubanyi, P. (1965). Bsitrăge zur Neurohistologie des Megaösophagus. Acta Neuroveg. (Wien), 27, 348-358.

Carison, A. J., and Luckhardt, A. B. (1921). Studies on the visceral sensory nervous system $X$ The vagus control of of the oesophagus. Amer.J. Physiol., 57, 299-335.

Carlson, A. J., Boyd, T. E., and Pearcey, J. F. (1922). Studies on the visceral and sensory nervous system. XIV.The reflex control of the cardia and lower end of the esophagus in mammals. Arch. intern. Med., 30, 409-433.

Carveth, S. W., Schlegel, J. F., Code, C. F., and Ellis, F. H., Jr. (1960). Changes in the motor activity of the esophagus and the gastroesophageal sphincter after vagotomy in dogs. Surg. Forum, 11, 311-313.

Cassella, R. R., Brown, A. L., Jr., Sayre, G. P., and Ellis, F. H., Jr. (1964). Achalasia of the esophagus, pathologic and etiologic considerations. Ann. Surg., 160, 474-485.

Heyrovsky, H. (1911). Casuistik und Therapie der idiopathischen Dilatation der Spsiszohre Oesophago-gastroanastomose. Arch. klin. Chir., 100, 703-715.

Higgs, B., Kerr, F. W. L., and Ellis, F. H., Jr. (1965). The experimental production of esophageal achalasia by electrolytic lesions in the medulla. J. thorac. cardiovasc. Surg., 50, 613-624.

Honjin, R. (1951). Studies on the nerve endings in the small intestine. Cytol. and Neurol. Studies, 9, 1-14.

Hurst, A. F., and Rake, G. W. (1930). Achalasia of the cardia, Quart. J. Med., 23, 491-507.

Iordanskaia, N. I. (1962). Functional disorders of the vagus nerves in cardiospasm. Vestn Khir., 88, 24-28.

Kimura, K. (1929). The nature of idiopathic esophagus dilatation.
Jap. J. Gastroent., 1, 199-207.

Knight, G. C. (1934). The innervation of the oesophagus and cardiac sphincter. J. Physiol. (Lond.). 81, 6-7.

Kraus, F. (1902). Krankheiten der Oesophagus, p. 131. Nothnagel Handbuch, Wien.

Lendrum, F. C. (1937). Anatomic Features of the cardiac orifice of the stomach. Arch. intern. Med., 59, 474-511.

Loeper, M., and Forestier, J. (1921). Les lésions nerveuses de pneumogastriou et le cardiospasme récurrent dans lu cancer de l'estomac. Arch. Mal. Appar. dig., 11, 307-312.

Long, D. M., Nice, C. M., Jr., Thal, A. P., and Truex, R. C. (1958). The experimental production of cardiospasm in dogs. Surg. Forum, 9, 408-411.

Misiewicz, J. J., Waller, S. L., Anthony, P. P., and Gummer, J. W. P. (1969). Achalasia of the cardia. Pharmacology and histopathology of isolated cardiac sphincteric muscle from patients with and without achalasia. Quart. $J$. Med., 38, 17-30.

Rake, G. W. (1926). A case of annular muscular hypertrophy of the oesophagus (achalasia of the cardia without oesophageal dilatation). Guy's Hosp. Rep., 76, 145-152.

Smith, B. (1967). Myenteric plexus in Hirschsprung's disease. Gut, 8, 308-312.

Symonds, C. quoted by Hurst and Rake (1930).

Trounce, J. R., Deuchar, D. C., Kauntze, R., and Thomas, G. A. (1957). Studies in achalasia of the cardia. Quart. J. Med., 26, 433-443.

Woolam, G. L., Maher, F. T., and Ellis, F. H., Jr. (1967). Vagal nerve function in achalasia of the oesophagus. Surg. Forum, 18, 362-365.

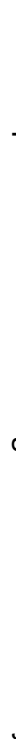

